\title{
56. A Karyotype Study of Eleven Species of Labrid Fishes from Japan
}

\author{
By Yoshio OJIma and Eiji Kashiwagi \\ Department of Biology, Faculty of Science, \\ Kwansei Gakuin University, Nishinomiya
}

(Communicated by Sajiro Makino, M. J. A., June 12, 1979)

Approximately 20000 species of fishes have been known to distribute in the world. They are represented by 6000 species from freshwater and 14000 species from saltwater. The number of species in which the chromosome number has been known is only about 900 species, and in about 700 species amongst them complete karyotypings have been made.

According to Gosline (1971) the teleostean fishes were classified into the following three larger groups: The lower group including Salmoniformes, Cypriniformes, etc.; the intermediate group represented by Cyprinodontiformes, etc.; and the higher group involving Perciformes, etc.

The Labridae belongs to Perciformes of the higher group. The members of the Japanese Labridae are represented by 4 subfamilies, 28 genera and 94 species. In this study, the karyotypes of 11 labrid fishes from Japan were investigated with special reference to the relation to the evolutional change of karyotype in comparison with that of some other teleosts.

Materials and methods. The following 8 species of the subfamily Corinae such as Thalassoma lunare (Otome-bera); T. lutescens (Yamabuki-bera); Pseudolabrus japonicus (Sasanoha-bera); Labroides dimidiatus (Honsomewake-bera); Stethojulis interrupta (Kaminari-bera) ; Halichoeres tenuispinnis (Hon-bera); H. prosopein (Munaten-bera) ; and Coris multicolor (Suji-bera), and 3 species of the subfamily Cheilininae such as Cirrhilabrus temminckii (Itohikibera) ; Hemipteronotus dea (Tens), and Cheilinus bimaculatus (Takobera) provided materials for this study.

The fishes were obtained in the Kushimoto Marine Park, Kushimoto, Wakayama Prefecture, Japan.

Kidney tissues were removed, minced with scissors and suspended in fish-BSS. Following the treatments with colchicine $(0.5 \mathrm{~g} / \mathrm{ml})$ for $30 \mathrm{~min}$ at room temperature, and $\mathrm{KCl}$-hypotonization $(0.075 \mathrm{M})$ for 15-30 min, they were fixed with Carnoy-solution as usual, air-dried and Giemsa-stained. Nomenclature of the chromosomes followed the 
system of Levan et al. (1964).

Results and remarks. The somatic metaphases from the eleven species under study are shown in Figs. 1 to 11, together with summarized data arranged in Table I. Further, modal karyograms of each species are reproduced in Figs. 12-21. Examinations of male and female specimens in each species have failed to detect any sexual difference of chromosomes so far as studies were concerned.
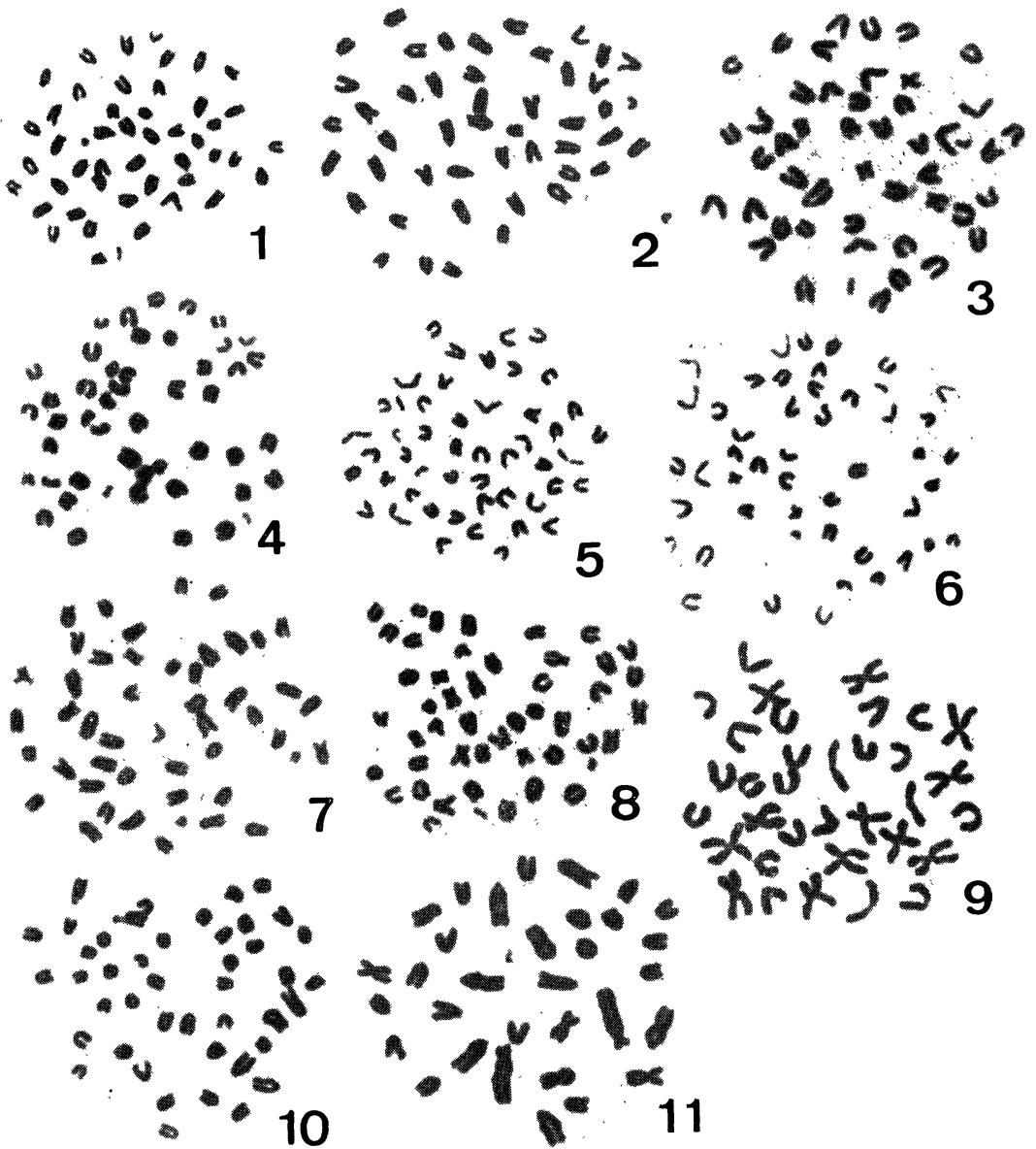

Figs. 1-11. Photomicrographs of chromosomes of eleven species of Labrid fishes studied. 1: Thalassoma lunare (Otome-bera). 2: T. lutescens (Yamabuki-bera). 3: Pseudolabrus japonicus (Sasanohabera). 4: Labroides dimidiatus (Honsomewake-bera). 5: Stethojulis interrupta (Kaminari-bera). 6: Halichoeres tenuispinnis (Hon-bera). 7: H. prosopein (Munaten-bera). 8: Coris multicolor (Suji-bera). 9: Cirrhilabrus temminckii (Itohiki-bera). 10: Hemipteronotus dea (Tens). 11: Cheilinus bimaculatus (Tako-bera). 
Table I. Karyotype constitution of 11 species of the Labridae studied

\begin{tabular}{lcccc}
\hline Corinae: & CN & M & SM & AT \\
Thalassoma lunare & 48 & 0 & 0 & 48 \\
Thalassoma lutescens & 48 & 0 & 0 & 48 \\
Pseudolabrus japonicus & 48 & 2 & 2 & 44 \\
Labroides dimidiatus & 48 & 0 & 0 & 48 \\
Stethojulis interrupta & 48 & 0 & 2 & 46 \\
Halichoeres tenuispinnis & 48 & 0 & 2 & 46 \\
Halichoeres prosopein & 48 & 0 & 2 & 46 \\
Coris multicolor & 48 & 6 & 8 & 34 \\
Cheilininae: & & & & \\
Cirrhilabrus temminckii & 34 & 12 & 0 & 22 \\
Hemipteronotus dea & 44 & 0 & 0 & 44 \\
Cheilinus bimaculatus & 32 & 4 & 2 & 26 \\
\hline
\end{tabular}

CN: Chromosome number. M: Metacentrics. SM: Submetacentrics. AT:

Acro-telocentrics.

Corinae: The following two species of the genus Thalassoma, $T$. lunare (Otome-bera) and T. lutescens (Yamabuki-bera), showed 48 chromosomes in diploid. The karyotype comprised 48 acro-telocentric chromosomes in both species (Figs. 1, 2 and 12). The diploid number of Pseudolabrus japonicus (Sasanoha-bera) was 48 which consisted of 2 metacentrics, 2 submetacentrics and 44 acro-telocentrics (Figs. 3 and 13). Labroides dimidiatus (Honsomewake-bera) had 48 chromosomes in diploid, all of which were of acrocentric nature (Figs. 4 and 14). Comparison with the chromosomes of Thalassoma revealed no apparent difference. The diploid number of Stethojulis interrupta (Kaminari-bera) was 48 which were represented by 2 submetacentrics and 46 acro-telocentrics (Figs. 5 and 15). Two species, Halichoeres tenuispinnis (Hon-bera) and H. prosopein (Munaten-bera), were found to possess $2 n=48$ chromosomes (Figs. 6 and 7). The karyotype comprised 2 submetacentrics and 46 acro-telocentrics (Fig. 16). Coris multicolor (Suji-bera) showed also 48 chromosomes, but they were classified into 6 metacentrics, 8 submetacentrics and 34 acro-telocentrics (Figs. 8 and 17).

Cheilininae: This group is particularly noted by variable chromosome morphology. Cirrhilabrus temminckii (Itohiki-bera) possessed the diploid number of 34 (Fig. 9). Morphologically they appeared to be 12 metacentrics and 22 acro-telocentrics (Fig. 18). Further, interesting is the fact that the size of chromosomes was very large in contrast to that of the other Corinae fishes. Hemipteronotus dea (Tens) was remarkable by 44 diploid chromosomes, all being of acrotelocentric structure (Figs. 10 and 19). Furthermore, Cheilinus bimaculatus (Tako-bera) was outstanding by 32 diploid chromosomes consisting of 4 metacentrics, 2 submetacentrics and 26 acro-telocentrics 
(Figs. 11 and 20).

The chromosome numbers of teleostean fishes seem to be parallel to the Gosline classification system: The chromosome numbers of the lower groups vary in range from $2 n=22$ (Umbra pygmaea) to $4 n=$
4
Q
A 1 A
11 a
n
1100
a
A
a $\wedge$ a
a
a ก ก
ด.
$\circ \bullet$
A ค 1
12

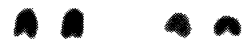

a)

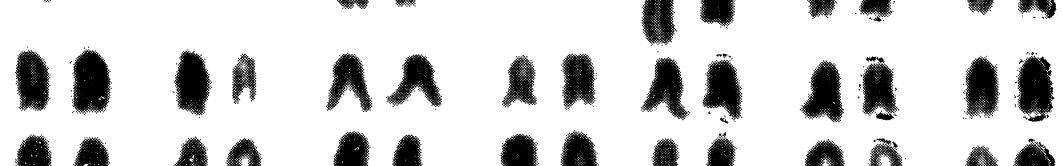

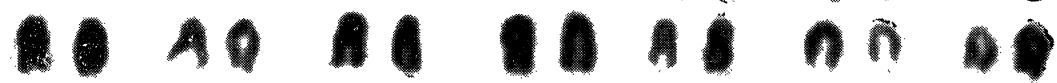

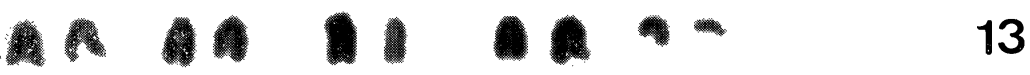

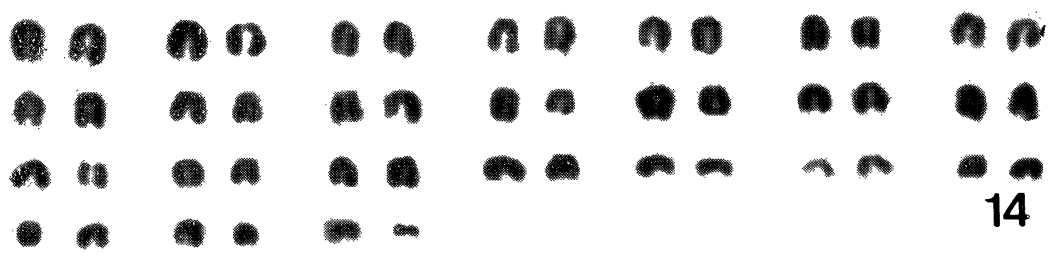

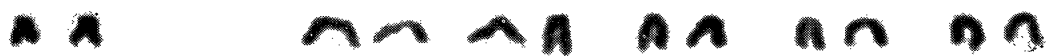

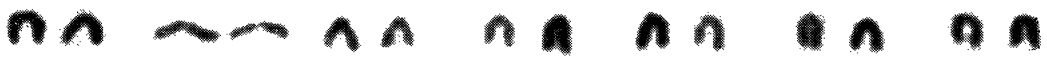

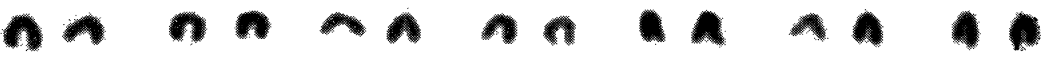

- $ค \wedge \sim \wedge \sim \rightarrow 15$

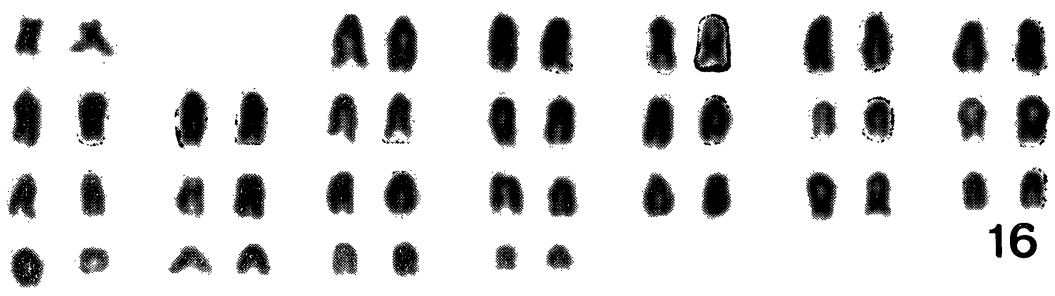

Figs. 12-20. Serial alignments of somatic chromosomes corresponding to Figs. 2-5, 7-10 and 11. 
206 (Carassius auratus langsdorfii). The wide distributions of the chromosome numbers with three low peaks at $50(33 \%), 48(9 \%)$ and $100(7 \%)$ are characteristic to this group. The chromosome numbers of the intermediate group ranged from $2 n=18$ (Aphyosemion christyi) to $2 n=69$ (Poecillia formosa). The peak chromosome number was found at $2 n=48(48 \%)$ in this group. The higher group shows a variation from $2 n=16$ (Sphaerichthys osphromonoides) to $2 n=78$ (Channa gachua) in the chromosome number. The peak number of this group was noted as $2 n=48(53 \%)$.

The noticeable picture relating to the evolutional process from the intermediate to higher steps is that the chromosome numbers show a gradual concentration into $2 n=48$. We expect to discover any

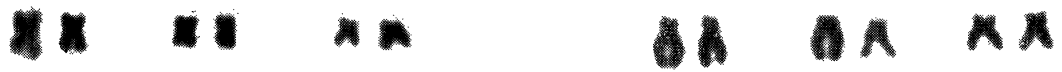

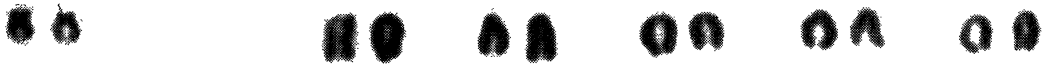

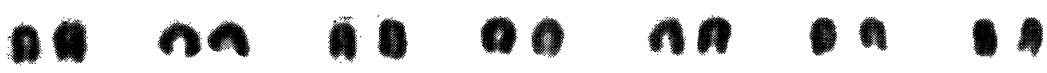 \\ ด * A ค แ - * 17}
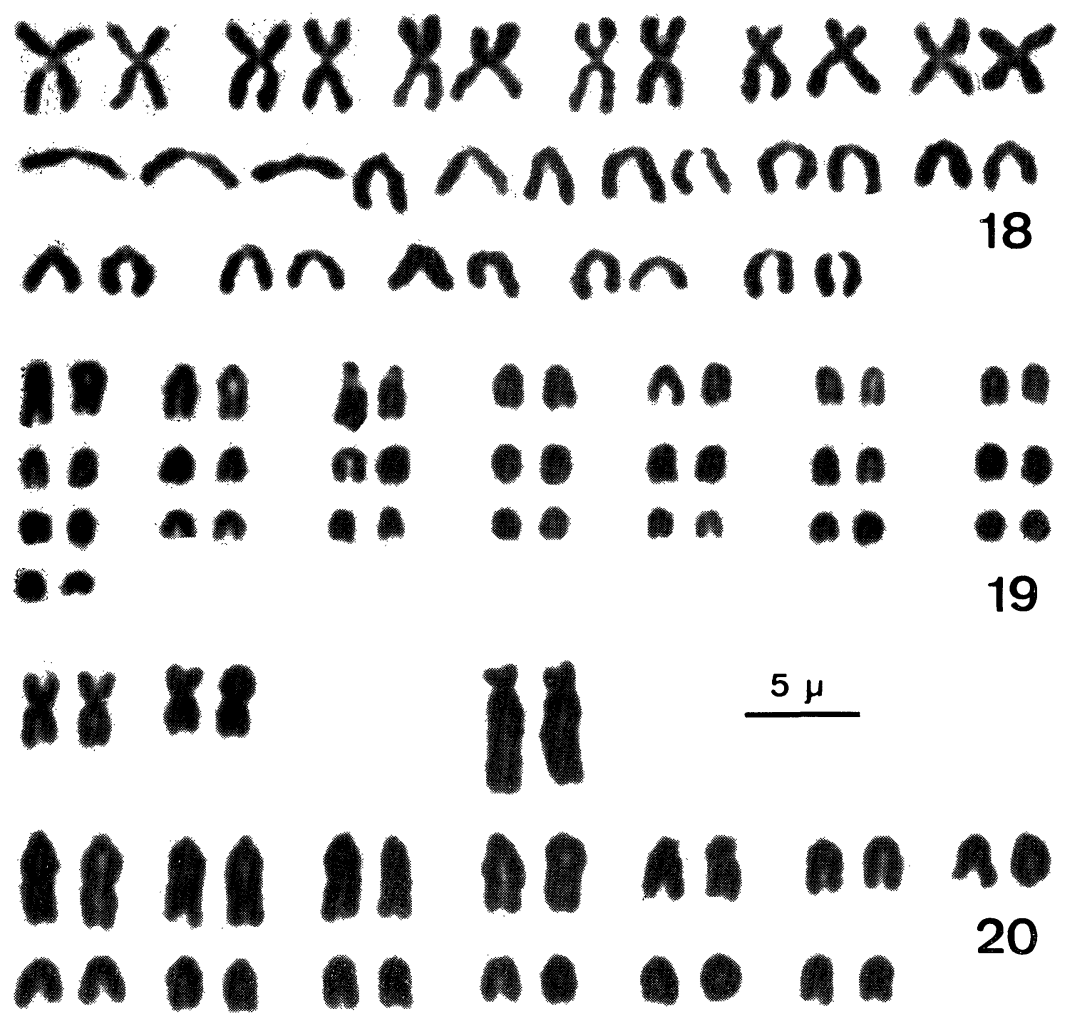
evidence to establish that the chromosome numbers would be spread towards smaller numbers than $2 n=48(<2 n=48)$.

Statistically, it is a general feature that meta-, or submetacentric chromosomes appear only in the lower group, whereas acrotelocentrics occur in the intermediate and higher groups.

Several problems arise in relation to the chromosome morphology of the fishes of Cheilininae. The karyological pattern of the Cheilininae belongs to the lower group's type viewed from the number and shape. It seems to be that now and still fish group evolution has been within the concussive whirlwind of discussion.

Summary. The chromosomes of 11 Japanese species of the Labridae are investigated, with reference to the evolutional relationship. The results are given in Table I.

Acknowledgment. We are very indebted to Dr. Sajiro Makino, M. J.A., Professor Emeritus, Hokkaido University, for improvement of the manuscript with critical revision of data.

\section{References}

Gosline, W. A. (1971) : Functional Morphology and Classification of Teleostean Fishes, University Press of Hawaii.

Levan, A., K. Fredga, and A. A. Sandberg (1964) : Nomenclature for centromeric position on chromosomes. Hereditas, 52, 201-220. 